\title{
Multi-drug resistant gram negative infections and use of intravenous polymyxin B in critically ill children of developing country: retrospective cohort study
}

\author{
Naveed-ur-Rehman Siddiqui', Farah Naz Qamar, Humaira Jurair and Anwarul Haque
}

\begin{abstract}
Background: Patients in pediatric intensive care Units (PICU) are susceptible to infections with antibiotic resistant organisms which increase the morbidity, mortality and cost of care.

To describe the clinical characteristics and mortality in patients with Multi-Drug Resistant (MDR) gram negative organisms. We also report safety of Polymyxin B use in these patients.

Methods: Files of patients admitted in PICU of Aga Khan University Hospital, from January 2010 to December 2011, one month to 15 years of age were reviewed. Demographic and clinical features of patients with MDR gram negative infections, antibiotic susceptibility pattern of isolates, discharge disposition and adverse effects of Polymyxin B were recorded.

Results: A total of 44.8/1000(36/803) admitted patients developed MDR gram negative infections, of which 47.2\% (17/36) were male, with mean age of $3.4 \mathrm{yrs}(+/-4.16)$. Acinetobacter Species (25.5\%) was the most frequently isolated MDR organisms followed by Klebsiella Pneumoniae (17\%). Sensitivity of isolates was $100 \%$ to Polymyxin B, followed by Imipenem (50\%), and piperacillin/tazobactem (45\%). The crude mortality rate of patients with MDR gram negative infections was 44.4\% (16/36). Fourteen of 36 patients received Polymyxin B and 57.1\%; (8/14) of them were cured. Nephrotoxicity was observed in $21.4 \%$ (3/14) cases, none of the patients showed signs of neuropathy.

Conclusion: Our study highlights high rates of Carbapenem resistant gram negative isolates, leading to increasing use of Polymyxin B as the only drug to combat against these critically ill children. Therefore, we emphasizeon Stewardship of Antibiotics and continuous surveillance system as strategies in overall management of these critically ill children.
\end{abstract}

Keywords: Pediatric intensive care unit (PICU), Multi-drug resistance (MDR), Gram negative organism, Polymyxin B

\section{Background}

The emergence of bacterial resistance is a threat particularly in Intensive Care Units (ICUs) settings, where these organisms are prevalent and their treatment becomes a challenge [1]. Multi-Drug Resistant (MDR) Staphylococcus Aureus particularly -- - Methicillin Resistant Staphylococcus Aureus (MRSA) has been in the limelight for long and has been controlled in high income countries to some extent by stringent infections control measures. However,

\footnotetext{
*Correspondence: drnrsvd@hotmail.com

Department of Pediatrics and child Health, Aga Khan University, Stadium Road, PO Box 3500, Karachi 74800, Pakistan
}

less attention has been given to gram negative infections until recently, when antimicrobial resistance among gram negative organisms and their spread raised serious public health concerns [2-4].

High rates of antibiotic resistant pathogens have been reported globally, in particular there are reports of rising trends from low and low middle income countries (LMIC) [4]. The most concerning fact is the development and spread of Klebsiella Pneumoniae Carbapenemase(KPC), Carbapenemase Resistant Enterobacteriacea (CRE) which leave very few antibiotic choices. Rates of resistance are much higher in critically ill patients. Resistance to Imipenem 
for bloodstream isolates of Acinetobacter Baumannii from ICU patients has been reported to be as high as 85\% [5]. Similarly, high resistance rates for P. Auregunosa isolates to Imipenem and quinolones have been reported [6,7]. gram negative pathogens that are resistant to polymyxin are also being reported from many countries and are a cause of mortality and high health care costs [8-10]. The reasons for development of resistance are numerous and related to antibiotic overuse and misuse in conjunction with poor infection control practices in health care settings [11]. The development of resistance to almost all classes of antibiotics is an alarming situation leaving physicians with only few treatment options [1]. Development of new antibiotics is limited and can be realized from the fact that only 5 new antibiotics have been developed and approved for use in the last decade [3]. Consequently there has been a resurgence of old antibiotics such as polymyxin as last resort for the treatment of infections caused by MDR gram negative pathogens [12-15].

The rising trend of highly resistant gram negative infections has also been described in our country [16-18]. 94\% and $75 \%$ of the total gram negative isolates were resistant to one or more antibiotics at the level of $10 \mathrm{ug} / \mathrm{ml}$ and $30 \mathrm{ug} / \mathrm{ml}$ respectively [17]. But these studies were done in adults and neonatal age group [16-18]. As there is lack of data among pediatric age group especially in critically ill children, so we aim to describe the clinical characteristics, antibiotic sensitivity pattern and mortality in patients with Multi-Drug Resistant (MDR) gram negative organisms, and also report the safety of polymyxin B use among critically ill pediatric patients.

\section{Methods}

Files of all patients admitted in the PICU of Aga Khan University Hospital, from January 2010 to December 2011, aged one month to 15 yrs were reviewed. The study was approved by Ethical Review Committee of Aga Khan University Hospital for the review of patients medical record. (2736-PED-ERC-13) As per policy of PICU, blood and urine cultures of all cases were sent at the time of admission to PICU. CSF cultures were sent for all sick infants $<3$ months of age and in older children if signs and symptoms of meningitis were present. Tracheal cultures were sent by tracheal aspiration for all ventilated patients after 48 hours of intubation or earlier if clinical signs are suggestive of chest infection were present.

All cultures were performed in the clinical laboratory of Aga Khan University Hospital using standard laboratory methods and susceptibility was performed according to CLSI guidelines [19]. For blood cultures, Bactec 9240 blood culture instrument was used. gram staining was performed on positive cultures in order to identify the organisms likely to be present. After identification conventional biochemical tests were done to identify the specific gram negative organism. If not identified, organisms were then identified on analytical profile index (ANI) on BioMerieux. For Urinary tract infections (UTIs), all specimens were inoculated on cysteine lactose Electrolyte Deficient (CLED) Agar. If identified any growth $>10^{5} \mathrm{CFU} / \mathrm{ml}$, was identified, gram staining was done, followed by conventional biochemical tests to identify the specific gram negative organisms. For respiratory secretions (tracheal \& bronchoalveolar lavage), all specimens were inoculated for quantitative culture, if identified $10^{5}-10^{4} \mathrm{CFU} / \mathrm{ml}$, then gram staining was done followed by conventional biochemical test to identify specific gram negative organisms. For wound cultures, specimens (swabs/tissues/pus) were inoculated for semiquantitative cultures. If growth occured, gram staining was done, followed by conventional biochemical tests to identify the specific gram negative organisms. Antibiotic susceptibility testing was done by Kirby-Bener's disk diffusion method and $\mathrm{E}$ test for all the isolated bacteria on Mueller Hinton Agar (MHA) to determine their resistance pattern against common antibiotics following standards of clinical laboratory standard institute (CLSI, formerly National Committee for Clinical Laboratory Standards [NCCLS]) [19,20]. Multidrug resistant organisms with resistance to imepenem were tested for sensitivity to polymyxin B. A colony count of $10^{5}$ in tracheal culture was considered significant

\begin{tabular}{ll} 
Table 1 Clinical characteristics of critically ill pediatric \\
patients with MDR-Gram negative infections \\
\hline Characteristics & $\mathbf{n = 3 6} \mathbf{n}(\%)$ \\
\hline Height in cms (Mean+/- SD) & $79.55(+/-31.2)$ \\
Weight in kg (Mean+/- SD) & $11.7(+/-11.4)$ \\
Ages in yrs. (Mean +/- SD) & $3.4(+/-4.16)$ \\
$<1$ year & $19(52.7 \%)$ \\
1-5 years & $7(19.4 \%)$ \\
$>5$ years & $10(27.8 \%)$ \\
Gender & \\
Male & $17(47.2 \%)$ \\
System Involved & \\
CVS & $14(38.9 \%)$ \\
CNS & $7(19.4 \%)$ \\
Respiratory & $6(16.7 \%)$ \\
MOD & $3(8.3 \%)$ \\
Hematological Malignancies & $2(5.6 \%)$ \\
Renal & $1(2.8 \%)$ \\
GIT & $1(2.8 \%)$ \\
Others & $2(5.6 \%)$ \\
Outcome & \\
Discharged & $20(55.6 \%)$ \\
Expired & $16(44.4 \%)$ \\
\hline
\end{tabular}

MDR: Multi-Drug resistant, CVS: Cardiovascular system, CNS: Central nervous system, MOD: Multi-organ dysfunction, GIT: Gastrointestinal tract. 
[21]. Culture proven sepsis was defined as one or more positive blood culture collected during stay in the PICU. Diagnosis of coagulase-negative staphylococcal sepsis required at least 2 positive blood cultures [22]. For each patient, positive cultures from each site were counted as separate events. All information was recorded on a structured proforma. The information collected included demographic characteristics of patients, site of infection, antibiotic sensitivity of the isolate and the mortality rate among the infected patients. MDR was defined as resistance to 3 or more antimicrobial groups against which it has been tested [23]. Final disposition was defined as death related to infection (death in the setting of clinical evidence of active infection or within 5 days after the last positive culture result), death unrelated to infection (death after an episode of infection but due to causes independent of the infectious process), or survival. Mortality was calculated by dividing the number of patients who died within 5 days of an infection with MDR-gram negative infections by the total number of subjects with MDR-gram negative infection. Data on polymyxin B use among these patients, (dose, prior and concomitant antibiotic use and, development of nephrotoxicity) was also recorded. Nephrotoxicity was assessed by the measurement of serum creatinine levels before and after the use of polymyxin $\mathrm{B}$, and an increase of $100 \%$ serum creatinine level from the baseline was considered as a marker for nephrotoxicity. Evaluation of neurotoxicity was analyzed by going through the recorded information on neurological examination before and after the use of polymyxin B. The development of neurological signs after the start of polymyxin in the absence of any other precipitating cause was taken as a marker for neurotoxicity due to polymyxin $\mathrm{B}$. The mortality rate amongst patients in whom polymyxin $B$ was used, was also reported.

\section{Results}

A total of 803 patients were admitted in the PICU during the study period, of which 44.8/1000 (36/803) admitted patients developed 47 episodes of MDR-gram negative infections. Most $(47.2 \%, 17 / 36)$ were male, 52.7\% (19/36) being under 1 year of age with mean age of 3.4 years $(+/-4.16)$. The clinical and demographic characteristics of patients who developed MDR gram negative infections are shown in Table 1. Majority of the organisms were isolated from respiratory tract $59.6 \%(28 / 47)$ followed by bloodstream infection (BSI) 25.5\% (12/47), with Acinetobacter Species (25.5\%) being the most frequently isolated organism followed by Klebsiella Pneumoniae (17\%), Escherichia coli (14.9\%) and Pseudomonas Aeruginosa $12.8 \%$ as in Table 2 . The mortality rate among MDR-gram negative infective critically ill pediatric patients was $44.5 \%$ (16/36), $75 \%$ were under 1 year of age, as compared to overall mortality of $12.3 \%(99 / 803)$ in our unit. Isolates of Acinetobacter Species were resistant to all antibiotics including carbapenems and tazobactems and were sensitive only to polymyxin B (100\%) and tobramycin (66.6\%). Other organisms also showed variable degree of resistance to different classes of antibiotics, the frequency of sensitivities to the various groups of antibiotics are shown in Table 3. The characteristic of patients in whom polymyxin was used is shown in Table 4 . Nephrotoxicity was observed in $21.4 \%$ (3/14) patients, of them all died, none of the subjects developed clinical signs of neurotoxicity. The mortality rate among patients in whom Polymyxin B was used was $42.9 \%$ (6/14).

\section{Discussion}

We report a high incidence of MDR gram negative infections. In another cohort the cumulative incidence of gram negative blood stream infection was 5.4/1000 hospital admissions of which $39 \%$ were MDR gram negative isolates [24]. Another study in ours institute showed comparable incidence of 55/1000 of late onset Klebsiella Pneumoniae sepsis, of which $80 \%$ were resistant to multiple antibiotics, but this study involved only neonates [16]. Most of our patients were infants constituting $52 \%$, which

Table 2 Pathogens isolated with site of infections $(n=47)$

\begin{tabular}{|c|c|c|c|c|c|c|}
\hline Organisms & n (\%) & $\begin{array}{l}\text { Blood } \\
\text { n (\%) }\end{array}$ & $\begin{array}{l}\text { Respiratory } \\
\text { n (\%) }\end{array}$ & $\begin{array}{l}\text { Urine } \\
\mathrm{n}(\%)\end{array}$ & $\begin{array}{l}\text { Wound } \\
\text { n (\%) }\end{array}$ & $\begin{array}{l}\text { Blood + Respiratory } \\
\text { n (\%) }\end{array}$ \\
\hline Acinetobacter Species & $12(25.5 \%)$ & 2 & 8 & 0 & 0 & 2 \\
\hline Klebsiella Pneumoniae & $8(17.0 \%)$ & 0 & 7 & 0 & 0 & 1 \\
\hline Pseudomonas Aeruginosa & $6(12.8 \%)$ & 2 & 4 & 0 & 0 & 0 \\
\hline Escherichia Coli & $7(14.9 \%)$ & 3 & 2 & 2 & 0 & 0 \\
\hline Enterobacter Species & $5(10.6 \%)$ & 2 & 3 & 0 & 0 & 0 \\
\hline Stenotrophomonas Maltophilia & $4(8.5 \%)$ & 0 & 3 & 0 & 0 & 1 \\
\hline Burkholderia Cepacia & $2(4.3 \%)$ & 2 & 0 & 0 & 0 & 0 \\
\hline Pseudomonas Species & $3(6.4 \%)$ & 1 & 1 & 0 & 1 & 0 \\
\hline Total n (\%) & $47(100 \%)$ & $12(25.5 \%)$ & $28(59.6 \%)$ & $2(4.3 \%)$ & $1(2.1 \%)$ & $4(8.5 \%)$ \\
\hline
\end{tabular}


Table 3 Antibiotic sensitivity of the multi-drug resistant gram negative isolates

\begin{tabular}{|c|c|c|c|c|c|c|c|c|c|c|c|c|}
\hline Organisms & Pip/Taz & Imepenem & Polymyxin B & Gentamycin & Amikacin & Aztreonam & Ceftriaxone & Ceftazidime & Ofloxacin & Cefuroxime & Amp/clav & Tobramycin \\
\hline \multirow[t]{2}{*}{ Acinetobacter Species } & $0 / 12$ & $0 / 12$ & $12 / 12$ & $0 / 12$ & $0 / 12$ & $0 / 6$ & $0 / 12$ & $0 / 12$ & $0 / 12$ & $0 / 8$ & $0 / 2$ & $6 / 9$ \\
\hline & $(0 \%)$ & $(0 \%)$ & $(100 \%)$ & (0\%) & $(0 \%)$ & $(0 \%)$ & $(0 \%)$ & $(0 \%)$ & $(0 \%)$ & $(0 \%)$ & (0\%) & $(66.6 \%)$ \\
\hline \multirow[t]{2}{*}{ Klebsiella Pneumoniae } & $5 / 8$ & $6 / 8$ & $3 / 3$ & $0 / 8$ & $3 / 8$ & $0 / 8$ & $0 / 8$ & $0 / 2$ & $2 / 8$ & $0 / 7$ & $2 / 7$ & \\
\hline & $(62.5 \%)$ & $(75 \%)$ & $(100 \%)$ & (0\%) & $(37.5 \%)$ & (0\%) & $(0 \%)$ & $(0 \%)$ & $(25 \%)$ & $(0 \%)$ & $(28.6 \%)$ & \\
\hline \multirow[t]{2}{*}{ Pseudomonas Aeruginosa } & $3 / 5$ & $1 / 6$ & $5 / 5$ & $1 / 6$ & $2 / 6$ & $1 / 4$ & $0 / 3$ & $2 / 4$ & $1 / 6$ & $0 / 2$ & - & $0 / 1$ \\
\hline & $(60 \%)$ & $(16.7 \%)$ & $(100 \%)$ & $(16.7 \%)$ & $(33.3 \%)$ & $(25 \%)$ & $(0 \%)$ & $(50 \%)$ & $(16.7 \%)$ & $(0 \%)$ & & $(0 \%)$ \\
\hline \multirow[t]{2}{*}{ Escherichia Coli } & $5 / 7$ & $7 / 7$ & - & $5 / 7$ & $7 / 7$ & $0 / 7$ & $0 / 7$ & $0 / 1$ & $4 / 7$ & $0 / 6$ & $3 / 7$ & - \\
\hline & $(71.5 \%)$ & $(100 \%)$ & & $(71.5 \%)$ & $(100 \%)$ & $(0 \%)$ & $(0 \%)$ & $(0 \%)$ & $(57.2 \%)$ & $(0 \%)$ & $(42.8 \%)$ & \\
\hline \multirow[t]{2}{*}{ Enterobacter Species } & $3 / 4$ & $4 / 4$ & - & $1 / 5$ & $1 / 5$ & $0 / 4$ & $0 / 4$ & $0 / 1$ & $1 / 4$ & $0 / 4$ & $1 / 4$ & - \\
\hline & $(75 \%)$ & $(100 \%)$ & & (20\%) & $(20 \%)$ & $(0 \%)$ & $(0 \%)$ & $(0 \%)$ & $(25 \%)$ & $(0 \%)$ & $(25 \%)$ & \\
\hline \multirow[t]{2}{*}{ Stenotrophomonas Maltophilia } & $1 / 2$ & - & - & $0 / 1$ & $0 / 1$ & $0 / 2$ & $0 / 2$ & $1 / 2$ & $3 / 4$ & - & - & - \\
\hline & $(50 \%)$ & & & $(0 \%)$ & $(0 \%)$ & $(0 \%)$ & $(0 \%)$ & $(50 \%)$ & (75\%) & & & \\
\hline \multirow[t]{2}{*}{ Burkholderia Cepacia } & - & $1 / 2$ & - & - & - & - & - & $2 / 2$ & $2 / 2$ & - & - & - \\
\hline & & $(50 \%)$ & & & & & & $(100 \%)$ & $(100 \%)$ & & & \\
\hline \multirow[t]{2}{*}{ Pseudomonas Species } & $1 / 2$ & $2 / 3$ & $3 / 3$ & $1 / 3$ & $1 / 3$ & $0 / 3$ & $0 / 3$ & $0 / 1$ & $1 / 3$ & $0 / 1$ & - & $0 / 1$ \\
\hline & (50\%) & $(66.6 \%)$ & $(100 \%)$ & $(33.3 \%)$ & $(33.3 \%)$ & $(0 \%)$ & $(0 \%)$ & $(0 \%)$ & $(33.3 \%)$ & $(0 \%)$ & & (0\%) \\
\hline \multirow[t]{2}{*}{ n (\%) } & $18 / 40$ & $21 / 42$ & $23 / 23$ & $8 / 42$ & $14 / 42$ & $1 / 34$ & $0 / 39$ & $5 / 25$ & $14 / 46$ & $0 / 28$ & $6 / 20$ & $6 / 11$ \\
\hline & (45\%) & (50\%) & (100\%) & (19.1\%) & (35.8\%) & (3\%) & (0\%) & (40\%) & (30.5\%) & (0\%) & (30\%) & (54.6\%) \\
\hline
\end{tabular}

$\mathrm{Pip} / \mathrm{Taz}=$ Piperacillin/Tazobactem Amp/Clav = Ampicillin + Clavulanic acid 
Table 4 Characteristics of pediatric critically ill patients with MDR-Gram negative organism with Intravenous polymyxin $B$ use

\begin{tabular}{|c|c|}
\hline Characteristics & $n=14 n(\%)$ \\
\hline Age median (range) & 7 month ( 1 month - 12 yrs) \\
\hline \multicolumn{2}{|l|}{ Gender } \\
\hline Males & $7(50 \%)$ \\
\hline \multicolumn{2}{|l|}{ Underlying disease } \\
\hline CVS & $8(57.1 \%)$ \\
\hline CNS & $4(28.6 \%$ \\
\hline Respiratory & $2(14.3 \%)$ \\
\hline \multicolumn{2}{|l|}{ Site of infection } \\
\hline Respiratory & $11(78.6 \%)$ \\
\hline BSI & $1(7.1 \%)$ \\
\hline $\mathrm{BSI}+$ Respiratory & $2(14.3 \%)$ \\
\hline \multicolumn{2}{|l|}{ Isolated organisms in Blood $(n=3)$} \\
\hline Acinetobacter Species & 1 \\
\hline Pseudomonas Aeruginosa & 1 \\
\hline Klebsiella Pneumoniae & 1 \\
\hline \multicolumn{2}{|l|}{$\begin{array}{l}\text { Isolated organisms in respiratory } \\
\text { secretions }(n=15)\end{array}$} \\
\hline Acinetobacter Species & 9 \\
\hline Pseudomonas Aeruginosa & 4 \\
\hline Klebsiella Pneumoniae & 1 \\
\hline Enterobacter species & 1 \\
\hline $\begin{array}{l}\text { Antibiotics used prior to Polymyxin } \\
\text { B }\end{array}$ & $\begin{array}{l}\text { Ceftriaxone, Meropenem, } \\
\text { Vancomycin }\end{array}$ \\
\hline $\begin{array}{l}\text { Antibiotics used concomitantly with } \\
\text { Polymyxin B }\end{array}$ & $\begin{array}{l}\text { Meropenem, Vancomycin, } \\
\text { Tobramycin, Ciprofloxacin }\end{array}$ \\
\hline $\begin{array}{l}\text { PICU stay before instillation of IV } \\
\text { Polymyxin B in days median (range) }\end{array}$ & 7.0(1-17 days) \\
\hline $\begin{array}{l}\text { Duration of IV Polymyxin B } \\
\text { treatment in days median (range) }\end{array}$ & 8.5 (2-14 days) \\
\hline Dosage of Polymyxin B & 40,000 IU/kg/day \\
\hline Nephrotoxicity & $3(21.4 \%)$ \\
\hline $\begin{array}{l}\text { Serum creatinine before Polymyxin B } \\
\text { use }(\mathrm{mg} / \mathrm{dl}) \text { median (range) }\end{array}$ & $0.41(0.1-1.2)$ \\
\hline $\begin{array}{l}\text { Serum creatinine after Polymyxin B } \\
\text { use }(\mathrm{mg} / \mathrm{dl}) \text { median (range) }\end{array}$ & $0.55(0.1-1.6)$ \\
\hline Neurotoxicity & 0 \\
\hline \multicolumn{2}{|l|}{ Outcome } \\
\hline Expired & $6(42.9 \%)$ \\
\hline Survived & $8(57.1 \%)$ \\
\hline
\end{tabular}

is comparable to another study with $>50 \%$ patient sunder 2 years of age excluding the neonates [24].

Among the MDR-gram negative rods, Acinetobacter species followed by Klebsiella Pneumoniae, Escherichia coli, and Pseudomonas Aeruginosa were the most frequently isolated pathogens as reported earlier [25]. However in, another study Klebsiella Pneumonia and Psuedomonas were the most common MDR isolates [24]. Acinetobacter species that are drug resistant and hence difficult to treat are increasingly being reported [26-28]. Carbapenem resistant Klebsiella and pseudomonas are also on the rise. One study had shown an increasing trend of Klebsiella Pneumoniae resistance to Amikacin, Flouroquinolones, Piperacillin/Tazobactems, and Imipenem among neonates [16]. Another study in adults showed $94 \%$ of resistance at the level of $10 \mathrm{ug} / \mathrm{ml}$ and $75 \%$ of resistance at the level of $30 \mathrm{ul} / \mathrm{ml}$ among clinically isolated gram negative organisms [17]. According to a recent report from Centre for Disease Control and prevention (CDC), more than $70 \%$ of bacteria responsible for health-care associated infections (HAIs) are resistant to at least one of the antibiotics commonly selected to treat them [1]. Therefore, increasing use of broad spectrum antibiotics and lack of good stewardship has contributed to these MDR infections [29]. With limited antibiotic options, Implementation of good antibiotic stewardship program, Continuous surveillance System, and stringent infection control seem to be the best available option.

We report a high mortality rate of $42.9 \%$ in subjects with MDR gram negative infections of which $75 \%$ were less than 1 year of age as compared to the overall mortality rate of $12.3 \%$ in our unit. Earlier studies have reported an overall mortality between $10-53.6 \%$ [24,30-33]. However it is difficult to ascertain whether resistance was the cause of death or other correlates like severity of the underlying illness, prolonged antibiotic treatment and comorbidities played a role. The high rates of infection among critically ill patients are related to exposure to invasive procedures, underlying illness, prolonged ICU stay, antibiotic exposure and patient to patient spread [34].

With the exception of Tigecycline, a relatively recently approved antibiotic active against MDR Acinetobacter Baumannii, [35] no new antibiotic against the MDRgram negative bacteria is even in the drug development pipeline [36]. polymyxin B and colistin (Polymyxin E) are the two polymyxins used clinically; but the knowledge on pharmacokinetics and pharmacodynamics is extremely limited, [37] and most was obtained before 1980s $[12,15]$.

There are limited reports on use of polymyxin B in pediatric age group [30,31]. There were only few studies investigating the use of polymyxin B for the treatment of infections caused by MDR-gram negative pathogens, mostly Acinetobacter and Pseudomonas [38-40]. We report data of 14 critically ill pediatric patients, who received intravenous polymyxin $B$ but despite this almost half of them expired. Previously reported mortality rate among MDR-gram negative infective patients with Polymyxin use was $20-54 \%$ [38-41] which is comparable to our data. However it is tough to decide whether the 
Polymyxin B was the cause of death or other risk factors like severity of the underlying disease and comorbidities etc. played a role. Nephrotoxicity and neurotoxicity were the most potential toxicities with parenteral administration of Polymyxin B $[15,42]$. Incidence of nephrotoxicity ranges from $0-37 \%$ [42]. We observed a similar rate of nephrotoxicity. It is difficult to ascertain whether this was due to progression of the acute kidney injury due to underlying disease or due to the use of other nephrotoxic drug concomitantly used with Polymyxin or primarily an adverse effect of Polymyxin B itself. Neurotoxicity due to Polymyxin B is usually mild and resolves after discontinuation of therapy [42]. Signs of Polymyxin B induced neurotoxicity include dizziness, generalized muscle weakness, facial or peripheral paresthesia, partial deafness, visual disturbances, vertigo, confusion, hallucinations, seizures, ataxia, and neuromuscular weakness [39]. However, we did not find any neurotoxicity associated with the use of intravenous Polymyxin B.

The limitations of this study are a retrospective collection of data, limited sample size limiting determination of risk factors for mortality among MDR gram negative patients and inability to comment on the nephrotoxicity of polymyxin.

\section{Conclusion}

Our study highlights high rates of carbapenem resistant gram negative isolates, leading to increasing use of polymyxin B as only drug to combat against these critically ill children. Therefore, we stress on increasing stewardship of antibiotics and continuous surveillance system as strategies in overall management of these critically ill children.

\section{Competing interests}

The authors declare that they have no competing interests.

\section{Authors' contributions}

NS: conception and design, acquisition of data, analysis and interpretation of data, drafting the manuscript. FN: given final approval of the version to be published, questions related to the accuracy or integrity of any part of the work are appropriately investigated and resolved. AH: conception and design, questions related to the accuracy or integrity of any part of the work are appropriately investigated and resolved, $\mathrm{HJ}$ : Data collection and analysis. ERC approval was taken for the review of patient's record. ERC No: 2736-PED-ERC-13. All authors read and approved the final manuscript.

\section{Disclosure/support}

Dr Farah Qamar, received research training support from the National Institute of Health's Fogarty International Center (1 D43 TW007585-01). The sponsors did not have any role in study design, data analysis or report writing.

Received: 19 June 2014 Accepted: 10 November 2014

Published online: 28 November 2014

\section{References}

1. Siegel RE: Emerging gram-negative antibiotic resistance: daunting challenges, declining sensitivities, and dire consequences. Respir Care 2008, 53(4):471-479.

2. Fish DN, Ohlinger MJ: Antimicrobial resistance: factors and outcomes. Crit Care Clin 2006, 22(2):291-311. vii.
3. Talbot GH, Bradley J, Edwards JE Jr, Gilbert D, Scheld M, Bartlett JG: Bad bugs need drugs: an update on the development pipeline from the antimicrobial availability task force of the infectious diseases Society of America. Clin Infect Dis 2006, 42(5):657-668.

4. Laxminarayan R, Duse A, Wattal C, Zaidi AK, Wertheim HF, Sumpradit N, Vlieghe E, Hara GL, Gould IM, Goossens H, Greko C, So AD, Bigdeli M, Tomson G, Woodhouse W, Ombaka E, Peralta AQ, Qamar FN, Mir F, Kariuki S, Bhutta ZA, Coates A, Bergstrom R, Wright GD, Brown ED, Cars O: Antibiotic resistance-the need for global solutions. Lancet Infect Dis 2013, 13(12):1057-1098.

5. Souli M, Galani I, Giamarellou H: Emergence of extensively drug-resistant and pandrug-resistant Gram-negative bacilli in Europe. Euro Surveill 2008, 13(47).

6. National Nosocomial Infections Surveillance (NNIS): System Report, data summary from January 1992 through June 2004, issued October 2004. Am J Infect Control 2004, 32(8):470-485.

7. Rossolini GM, Mantengoli E: Treatment and control of severe infections caused by multiresistant Pseudomonas aeruginosa. Clin Microbiol Infect 2005, 11(Suppl 4):17-32.

8. Ko KS, Suh JY, Kwon KT, Jung SI, Park KH, Kang Cl, Chung DR, Peck KR, Song $\mathrm{JH}$ : High rates of resistance to colistin and polymyxin B in subgroups of Acinetobacter baumannii isolates from Korea. J Antimicrob Chemother 2007, 60(5):1163-1167.

9. Capone A, Giannella M, Fortini D, Giordano A, Meledandri M, Ballardini M, Venditti E, Bordi D, Capozzi MP, Balice A, Tarasi G, Parisi A, Lappa A, Carattoli $\mathrm{N}$, Petrosillo and on behalf of the SEERBIO-GRAB network: High rate of colistin resistance among patients with carbapenem-resistant Klebsiella pneumoniae infection accounts for an excess of mortality. Clin Microbiol Infect 2013, 19(1):E23-E30.

10. Kontopidou F, Plachouras D, Papadomichelakis E, Koukos G, Galani I, Poulakou G, Dimopoulos G, Antoniadou A, Armaganidis A, Giamarellou H: Colonization and infection by colistin-resistant Gram-negative bacteria in a cohort of critically ill patients. Clin Microbiol Infect 2011, 17(11):E9-E11.

11. Okeke IN, Klugman KP, Bhutta ZA, Duse AG, Jenkins P, O'Brien TF, Ariel P-M, Ramanan L: Antimicrobial resistance in developing countries. Part II: strategies for containment. Lancet Infect Dis 2005, 5(9):568-580. Epub 2005/08/27.

12. Evans ME, Feola DJ, Rapp RP: Polymyxin B sulfate and colistin: old antibiotics for emerging multiresistant gram-negative bacteria. Ann Pharmacother 1999, 33(9):960-967.

13. Hermsen ED, Sullivan CJ, Rotschafer JC: Polymyxins: pharmacology, pharmacokinetics, pharmacodynamics, and clinical applications. Infect Dis Clin N Am 2003, 17(3):545-562.

14. Falagas ME, Kasiakou SK: Colistin: the revival of polymyxins for the management of multidrug-resistant gram-negative bacterial infections. Clin Infect Dis 2005, 40(9):1333-1341.

15. Li J, Nation RL, Turnidge JD, Milne RW, Coulthard K, Rayner CR, Paterson DL: Colistin: the re-emerging antibiotic for multidrug-resistant Gram-negative bacterial infections. Lancet Infect Dis 2006, 6(9):589-601.

16. Saleem AF, Qamar FN, Shahzad H, Qadir M, Zaidi AK: Trends in antibiotic susceptibility and incidence of late-onset Klebsiella pneumoniae neonatal sepsis over a six-year period in a neonatal intensive care unit in Karachi, Pakistan. Int J Infect Dis 2013, 17(11):e961-e965.

17. Aman $U$, Rabia $D$, Inam $U$, Rafiq M: Antibiotic resistance profile of clinical gram negative bacteria. J Biol Food Sci Res 2012, 1(2):23-25. April 2012(2):23-5.

18. Irfan S, Idrees F, Mehraj V, Habib F, Adil S, Hasan R: Emergence of carbapenem resistant gram negative and vancomycin resistant gram positive organisms in Bacteremic isolates of febrile neutropenic patients: a descriptive study. BMC Infect Dis 2008, 8:80.

19. Wikler MA, Cockerill FR, Craig WA, Dudly MN, Eliopoulos MN, Hetch DW, Hindler JF, Low DE, Sheehan DJ, Tenover FC, Turnidge JD, Weinstein MP, Zimmer BL, Ferraro MJ, Swenson JM: Performance Standards for Antimicrobial Susceptibility Testing. 17th Information Supplement. 940 West Valley Road, Suit 1400, Wayne, Pennsylvania 19087-1998, USA: Clinical and laboratory standard institute; 2007:1-177. CLSI document M 100- S17. ISBN 1-56238-625-5.

20. Koneman EW, Allen SD, Janda WM, Scherckenberger PC, JWC W: Color Atlas and Textbook of Diagnostic Microbiology: Philadelphia Lippincott. 31 West Camden Street, Baltimore MD 21201: Lippincott, Williams and Wilkins; 2002

21. Sachdev A, Chugh K, Sethi M, Gupta D, Wattal C, Menon G: Diagnosis of ventilator-associated pneumonia in children in resource-limited setting: a comparative study of bronchoscopic and nonbronchoscopic methods. Pediatr Crit Care Med 2010, 11(2):258-266. 
22. Karlowicz MG, Buescher ES, Surka AE: Fulminant late-onset sepsis in a neonatal intensive care unit, 1988-1997, and the impact of avoiding empiric vancomycin therapy. Pediatrics 2000, 106(6):1387-1390.

23. Magiorakos AP, Srinivasan A, Carey RB, Carmeli Y, Falagas ME, Giske CG, Harbarth S, Hindler JF, Kahlmeter G, Olsson Liljequist B, Paterson DL, Rice LB, Stelling J, Struelens MJ, Vatopoulos A, Weber JT, Monnet DL: Multidrug-resistant, extensively drug-resistant and pandrug-resistant bacteria: an international expert proposal for interim standard definitions for acquired resistance. Clin Microbiol Infect 2012, 18(3):268-281.

24. Folgori L, Livadiotti S, Carletti M, Bielicki J, Pontrelli G, Degli Atti ML, Marta L, Bertaina C, Lucignano B, Ranno S, Carretto E, Muraca M, Sharland M, Bernaschi P: Epidemiology and clinical outcomes of multidrug-resistant gram-negative bloodstream infections in a european tertiary pediatric hospital during a 12-month period. Pediatr Infect Dis J 2014, 33(9):929-932.

25. Kucukates E: Antimicrobial resistance among Gram-negative bacteria isolated from intensive care units in a Cardiology Institute in Istanbul, Turkey. Jpn J Infect Dis 2005, 58(4):228-231.

26. Gaynes R, Edwards JR: Overview of nosocomial infections caused by gram-negative bacilli. Clin Infect Dis 2005, 41(6):848-854

27. Abbo A, Navon-Venezia S, Hammer-Muntz O, Krichali T, Siegman-Igra Y, Carmeli Y: Multidrug-resistant Acinetobacter baumannii. Emerg Infect Dis 2005, 11(1):22-29. Epub 2005/02/12

28. Navon-Venezia S, Ben-Ami R, Carmeli Y: Update on Pseudomonas aeruginosa and Acinetobacter baumannii infections in the healthcare setting. Curr Opin Infect Dis 2005, 18(4):306-313.

29. Kunz AN, Brook I: Emerging resistant Gram-negative aerobic bacilli in hospital-acquired infections. Chemotherapy 2010, 56(6):492-500.

30. Richards M, Thursky K, Buising K: Epidemiology, prevalence, and sites of infections in intensive care units. Semin Respir Crit Care Med 2003, 24(1):3-22.

31. Ylipalosaari P, Ala-Kokko TI, Laurila J, Ohtonen P, Syrjala H: Intensive care acquired infection is an independent risk factor for hospital mortality: a prospective cohort study. Crit Care 2006, 10(2):R66.

32. Goldmann DA, Pier GB: Pathogenesis of infections related to intravascular catheterization. Clin Microbiol Rev 1993, 6(2):176-192.

33. Ylipalosaari P, Ala-Kokko Tl, Laurila J, Ohtonen P, Syrjala H: Epidemiology of intensive care unit (ICU)-acquired infections in a 14-month prospective cohort study in a single mixed Scandinavian university hospital ICU. Acta Anaesthesiol Scand 2006, 50(10):1192-1197.

34. Shehabi AA IB: Microbial infection and antibiotic resistance patterns among Jordanian intensive care patients. East Mediterr Health J 1996, 2:515-520.

35. Pankey GA: Tigecycline. J Antimicrob Chemother 2005, 56(3):470-480.

36. Livermore DM: The need for new antibiotics. Clin Microbiol Infect 2004, 10(Suppl 4):1-9.

37. Tam VH, Schilling AN, Vo G, Kabbara S, Kwa AL, Wiederhold NP, Lewis RE: Pharmacodynamics of polymyxin B against Pseudomonas aeruginosa. Antimicrob Agents Chemother 2005, 49(9):3624-3630.

38. Ouderkirk JP, Nord JA, Turett GS, Kislak JW: Polymyxin B nephrotoxicity and efficacy against nosocomial infections caused by multiresistant gram-negative bacteria. Antimicrob Agents Chemother 2003, 47(8):2659-2662

39. Sobieszczyk ME, Furuya EY, Hay CM, Pancholi P, Della-Latta P, Hammer SM, Kubin $C J$ : Combination therapy with polymyxin B for the treatment of multidrug-resistant Gram-negative respiratory tract infections. $J$ Antimicrob Chemother 2004, 54(2):566-569.

40. Holloway KP, Rouphael NG, Wells JB, King MD, Blumberg HM: Polymyxin B and doxycycline use in patients with multidrug-resistant Acinetobacter baumannii infections in the intensive care unit. Ann Pharmacother 2006, 40(11):1939-1945.

41. Zavascki AP, Barth AL, Goncalves AL, Moro AL, Fernandes JF, Martins AF, Ramos F, Goldani LZ: The influence of metallo-beta-lactamase production on mortality in nosocomial Pseudomonas aeruginosa infections. J Antimicrob Chemother 2006, 58(2):387-392.

42. Falagas ME, Kasiakou SK: Toxicity of polymyxins: a systematic review of the evidence from old and recent studies. Crit Care 2006, 10(1):R27.

\section{doi:10.1186/s12879-014-0626-9}

Cite this article as: Siddiqui et al:: Multi-drug resistant gram negative infections and use of intravenous polymyxin B in critically ill children of developing country: retrospective cohort study. BMC Infectious Diseases 2014 14:626.

\section{Submit your next manuscript to BioMed Central and take full advantage of:}

- Convenient online submission

- Thorough peer review

- No space constraints or color figure charges

- Immediate publication on acceptance

- Inclusion in PubMed, CAS, Scopus and Google Scholar

- Research which is freely available for redistribution 